\title{
Natural course of subarachnoid hemorrhage is worse in elderly patients
}

\author{
A história natural da hemorragia subaracnóide é pior em pacientes idosos \\ Felix Hendrik Pahl, Matheus Fernandes de Oliveira, José Marcus Rotta
}

\begin{abstract}
Aging is a major risk factor for poor outcome in patients with ruptured or unruptured intracranial aneurysms (IA) submitted to treatment. It impairs several physiologic patterns related to cerebrovascular hemodynamics and homeostasis. Objective: Evaluate clinical, radiological patterns and prognostic factors of subarachnoid hemorrhage (SAH) patients according to age. Method: Three hundred and eighty nine patients with aneurismal SAH from a Brazilian tertiary institution (Hospital do Servidor Público Estadual de São Paulo) were consecutively evaluated from 2002 to 2012 according to Fisher and Hunt Hess classifications and Glasgow Outcome Scale. Results: There was statistically significant association of age with impaired clinical, radiological presentation and outcomes in cases of SAH. Conclusion: Natural course of SAH is worse in elderly patients and thus, proper recognition of the profile of such patients and their outcome is necessary to propose standard treatment.
\end{abstract}

Keywords: subarachnoid hemorrhage, aneurysm, age, outcome, treatment.

RESUMO

A idade é considerada fator de risco de mau prognóstico em pacientes com aneurismas intracranianos rotos ou não-rotos; com o aumento da idade, ficam prejudicados vários padrões fisiológicos relacionados à hemodinâmica cerebral e homeostase. Objetivo: Estudar o quadro clínico, os dados radiológicos e o prognóstico nos pacientes com hemorragia subaracnóide aneurismática em relação à idade. Método: Foram avaliados consecutivamente, de 2002 a 2012, 389 pacientes com hemorragia subaracnóide aneurismática oriundos de uma instituição terciária brasileira. Resultados: Houve associação da idade com pior quadro clínico, radiológico e prognóstico nos pacientes com hemorragia subaracnóide aneurismática. Conclusão: O curso natural da hemorragia subaracnoidea é pior em pacientes idosos. O reconhecimento adequado do perfil desses pacientes e seu prognóstico é importante para estabelecer um tratamento adequado.

Palavras-chave: hemorragia subaracnóide, aneurisma, idade, prognóstico, tratamento.

Aging is a major risk factor for poor outcome in patients with ruptured or unruptured intracranial aneurysms (IA) submitted to treatment $t^{1,2,3,4,5}$.

In those patients, there is increased impairment of consciousness, thick subarachnoid clot, intraventricular hemorrhage, acute hydrocephalus and higher probability of rebleeding after subarachnoid hemorrhage $(\mathrm{SAH})^{4}$. In the case of unruptured aneurysms, early and late complications are usually more severe in older patients, due to association with systemic morbidities and loss of adequate physiologic homeostasis ${ }^{2,3}$.

We present our series and report nuances in the characterization and outcome of patients with IA.

\section{METHOD}

Three hundred and eighty nine patients who suffered subarachnoid hemorrhage from a Brazilian tertiary institution (Hospital do Servidor Público Estadual de São Paulo) were consecutively evaluated from 2002 to 2012. Our analysis is a retrospective discussion, based in medical records.

Although the concept of elder patient varies (most developed countries consider over 65 years old and World Health Organization warrants over 60 years old), we have chosen the cutoff of 70 years old, which is the most addressed threshold in pertinent guidelines as a landmark for therapeutic decision of $\mathrm{IA}^{1,2}$.

Departamento de Neurocirurgia, Hospital do Servidor Público Estadual de São Paulo, Sao Paulo SP, Brazil.

Correspondence: Matheus Fernandes de Oliveira; Av. Luís Góis 1333 / ap. 23; 04043-150 São Paulo SP, Brasil; E-mail: mafernoliv@yahoo.com.br Conflict of interest: There is no conflict of interest to declare.

Received 10 July 2014; Received in final form 20 July 2014; Accepted 08 August 2014. 
Inclusion criteria: all patients diagnosed with ruptured intracranial aneurysms submitted to treatment based in surgical approach and/or endovascular approach.

Exclusion criteria: unruptured intracranial aneurysms.

SAH patients were divided in two groups. Group 1 was composed of patients 70 years old or above and group 2 was composed of patients below 70 years. They were submitted to complete neurological examination during hospitalization. At admission they were classified according to Fisher and Hunt-Hess (HH) classification. Treatment modalities were classified as surgical or endovascular. At discharge, they were classified according to Glasgow Outcome Scale (GOS).

This study was approved by Hospital do Servidor Público Estadual de São Paulo Ethics Committee and informed consent was obtained from each patient.

\section{Statistics}

In this study, numerical data are presented as mean \pm standard deviation or median with range when appropriate. Categorical data are presented as percentages. To determine the distribution of our data, the Kolmogorov-Smirnov Test was used. Statistical analysis was performed by Student's $t$-test and Chi-Square test when appropriate. Multiple logistic regression analysis was used to evaluate outcome in GOS. When comparing groups, the level of significance is considered when $\mathrm{p}<0.05$.

\section{RESULTS}

\section{Characterization of patients}

Three hundred and eighty nine patients have suffered SAH. Seventy two (18.5\%) were 70 years old or above (group 1) and 317 (81.5\%) were below 70 years old (group 2) (Table 1).

\section{Fisher classification}

Thirty one patients (43\%) in group 1 presented with Fisher 1 or 2.41 (57\%) patients in the same group presented with Fisher 3 or 4. In group 2, 213 patients (67\%) presented with Fisher 1 or 2 and $104(33 \%)$ with Fisher 3 or 4 . The

Table 1. Features of 389 subarachnoid hemorrhage (SAH) patients (age, gender, Fisher classification, Hunt Hess classification and treatment modality).

\begin{tabular}{lcccccc}
\hline Age (years) & $<7081.5 \%$ & $=$ or $>7018.5 \%$ & & & \\
\hline Gender & female & male & & & \\
& $74 \%$ & $26 \%$ & & & \\
Fisher & $\mathrm{I}$ & $\mathrm{II}$ & $\mathrm{III}$ & $\mathrm{IV}$ & \\
& $32 \%$ & $14 \%$ & $22 \%$ & $32 \%$ & \\
Hunt Hess & $\mathrm{I}$ & $\mathrm{II}$ & $\mathrm{II}$ & $\mathrm{IV}$ & $\mathrm{V}$ \\
& $28 \%$ & $38 \%$ & $15 \%$ & $5 \%$ & $14 \%$ \\
Treatment & surgery & endovascular & & & \\
& $90.7 \%$ & $9.3 \%$ & & & \\
\hline
\end{tabular}

FISHER CLASSIFICATION IN SAH

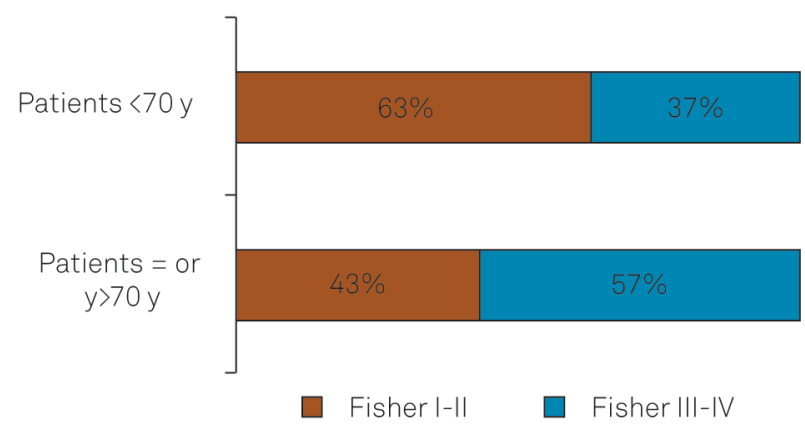

Figure 1. Fisher classification of subarachnoid hemorrhage (SAH) patients according to age.

distribution of the Fisher strata was different between groups $(\mathrm{p}=0.0002)$ (Figure 1$)$.

\section{Hunt Hess classification}

Twenty nine patients (40\%) in group 1 presented with Hunt Hess of 4 or 5 , and 43 patients $(60 \%)$ presented with $\mathrm{HH}$ of 1,2 or 3. In group 2, 48 patients (15\%) were HH 4 or 5 and 269 (85\%) were HH 1, 2 or 3 . The distribution of the Fisher strata was different between groups $(\mathrm{p}<0.0001)$ (Figure 2).

\section{Treatment modality}

The majority of patients in our sample (90.7\%) was submitted to surgical treatment, while few cases underwent endovascular management (9.3\%) (Table 1).

\section{Outcome in SAH}

In group 1, 58 out of 72 patients $(80.5 \%)$ developed GOS of 1,2 or 3 and 14 patients 4 or 5 (19.5\%). In group 2, 124 (39\%) developed GOS 1, 2 or 3 and 193 (61\%) 4 or five $(\mathrm{p}<0.0001)$ (Figure 3).

One hundred and three patients (26.5\%) were discharged in GOS 1, 2 and 3. Two hundred and eighty six (73.5\%) were discharged in GOS 4 or 5. Forty patients (38.8\%) discharged

H\&H CLASSIFICATION IN SAH

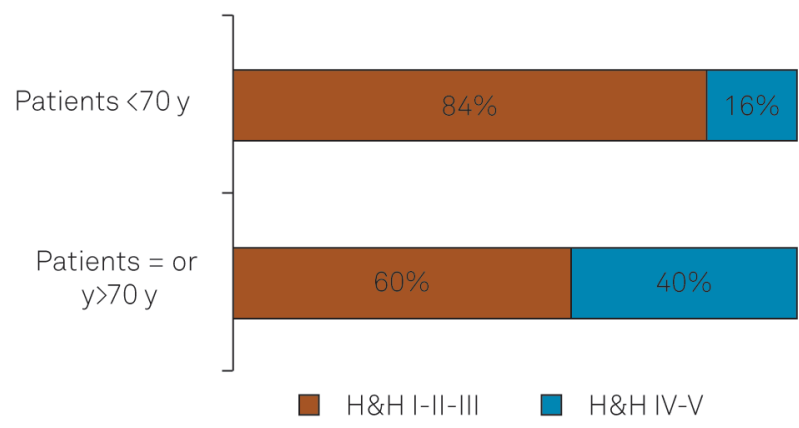

Figure 2. Hunt-Hess $(\mathrm{HH})$ classification of subarachnoid hemorrhage $(\mathrm{SAH})$ patients according to age. 
AGE AND OUTCOME IN SAH

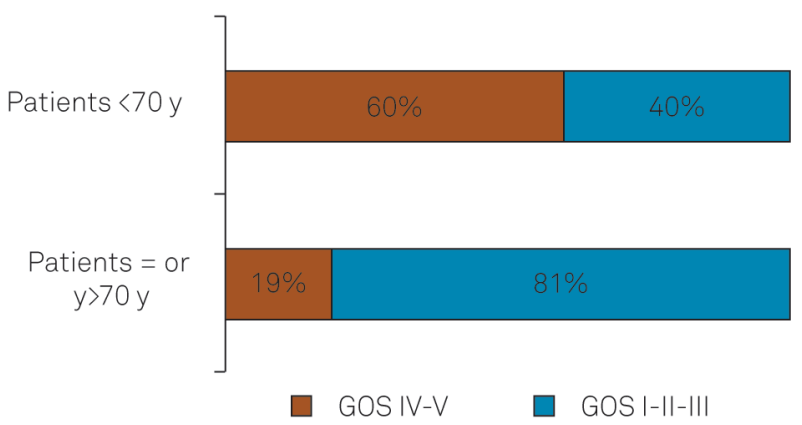

Figure 3. Age and glascow outcome scale (GOS) outcome in subarachnoid hemorrhage (SAH) patients.

with GOS 1, 2 and 3 presented initially with $\mathrm{HH}$ of 1,2 or 3 and 63 patients $(62.2 \%)$ with 4 or 5 . Among patients discharged with GOS 4 or 5, 275 (96\%) presented initially with $\mathrm{HH} 1,2$ or 3 and 11 patients (4\%) with $\mathrm{HH}$ of 4 or 5 $(\mathrm{p}<0.0001)$.

In group 1, 50 patients (69.5\%) were discharged in GOS 1 , 2 or 3 and $22(30.5 \%)$ in GOS 4 or 5 . Among GOS 1, 2 or 3 group, 22 (44\%) were $\mathrm{HH} 1,2$ or 3 and 28 (56\%) were $\mathrm{HH}$ 4 or 5 . Among GOS 4 or 5 group, 21 (95.5\%) were HH 1, 2 or 3 and 1 (4.5\%) was HH 4. The distribution of the Fisher strata was different between groups $(\mathrm{p}<0.0001)$.

In group 2, 51 patients (16\%) were discharged in GOS 1, 2 or 3 and $264(84 \%)$ in GOS 4 or 5 . Among GOS 1, 2 or 3 group, $18(35 \%)$ were $\mathrm{HH} 1,2$ or 3 and $35(65 \%)$ were $\mathrm{HH}$ 4 or 5 . Among GOS 4 or 5 group, 254 (96\%) were $\mathrm{HH} \mathrm{1,} 2$ or 3 and $10(4 \%)$ was HH $4(\mathrm{p}<0.0001)$.

Patients submitted to surgical treatment presented with better GOS $(p<0.05)$. Two hundred and fifty four patients submitted to surgery (72\%) were discharged in GOS 4 or 5. $28 \%$ were discharged in GOS 1, 2 or 3. In endovascular group, $81 \%$ (29 patients) were discharged in GOS 1, 2 or 3 and $19 \%$ in GOS 4 or 5 .

Female patients were $74 \%$ of the sample. There was no difference in GOS according to gender. When evaluating all variates together in multiple regression analysis, age, Fisher, Hunt Hess and treatment modality were associated with worse outcome. Age and Hunt Hess revealed the strongest association with worse GOS (Table 2).

Table 2. Statistical analysis in multiple logistic regression.

\begin{tabular}{lccc}
\hline Variate & $\begin{array}{c}\text { Odds } \\
\text { ratio }\end{array}$ & $\begin{array}{c}\text { Confidence interval } \\
(95 \% \mathrm{Cl})\end{array}$ & $\mathrm{p}$-value \\
\hline Age (years) & 7.5 & $5.3-10.6$ & $\mathrm{p}<0.0001$ \\
Gender & 1.2 & $0.7-1.4$ & $\mathrm{p}>0.05$ \\
Fisher & 2.4 & $1.9-2.8$ & $\mathrm{p}<0.01$ \\
Hunt Hess & 5.1 & $3.6-7.3$ & $\mathrm{p}<0.001$ \\
Treatment & 1.6 & $1.2-1.9$ & $\mathrm{p}<0.05$ \\
modality & & & \\
\hline
\end{tabular}

\section{DISCUSSION}

Our sample illustrates the strong association between age and poor outcomes when treating ruptured intracranial aneurysms. In summary, there was statistically significant association of age with impaired clinical and radiological presentation in cases of SAH and outcomes were worse in SAH patients. When age was analysed together with initial $\mathrm{HH}$ as an outcome predictor, age presented stronger impact with statistical significance.

Although most of our patients were female, there was no association of gender with clinical, radiological and/or outcome. Other factors like clinical comorbidities, may indeed interfere with presentation and outcomes.

The incidence of intracranial aneurysms rises with age, and the same behavior is true regarding $\mathrm{SAH}^{1,2,3,45}$. As a general rule, unruptured aneurysms have a $1 \%$ per year probability of bleeding. Thus, unruptured aneurysms greater than $10 \mathrm{~mm}$ should be treated at any age, due to risk of rupture. Aneurysms between 5-10 mm should be considered in a particular basis, once age and clinical morbidities may interfere with treatment ${ }^{2,3}$. Below $5 \mathrm{~mm}$, a more conservative approach is usually advocated. When SAH is present, these rationales are abandoned and prompt treatment must be achieved independently of aneurysm size ${ }^{1}$.

Several factors impact evaluation, treatment strategies and outcomes in intracranial aneurysmal disease. Aging probably is one of the most significant independent factors. It impairs several physiologic patterns related to cerebrovascular hemodynamics and homeostasis $6,7,8,9,10,11,12$.

There is a decline in cerebral blood flow velocity with age, which may be associated with certain changes as: decreased cerebral blood flow (CBF) or metabolic demands; vessel changes like progressive kinking, calcifications (Figure 4), elongation, stenosis and lower cardiac output ${ }^{1,2,3,11,13,14,15}$. It is also associated with a $20 \%$ to $30 \%$ decrease in CBF in healthy individuals between the ages of 20 and 80 years
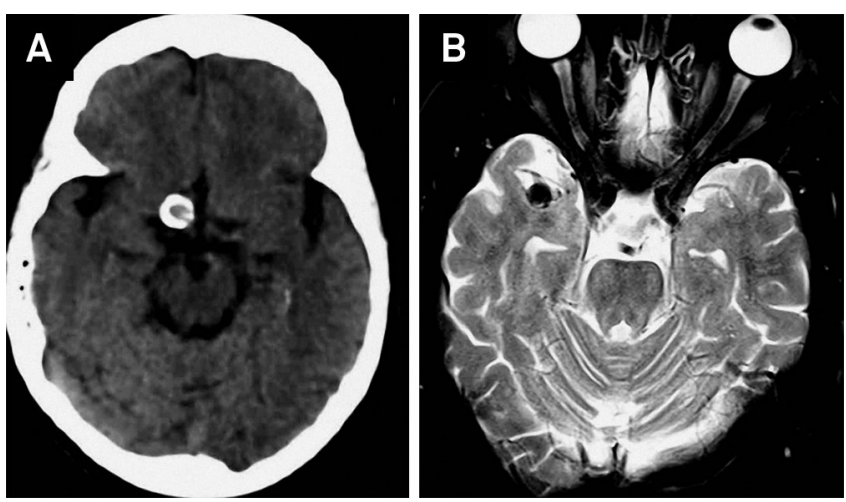

Figure 4. Two examples of calcified aneurysms in elderly patients. 
and with dilatation of major extracranial arteries and reduction of flow within parenchymal vessels ${ }^{1,13,14,15}$.

All those statements justify that elderly usually present with more severe SAH than younger patients, characterized by higher Fisher and Hunt Hess grades. After treatment, elderly are also prone to face severe neurological and systemic complications, like vasospasm, hydrocephalus, brain and heart ischemic insults and others ${ }^{6,7,8,9,10}$.

Cerebral vasospasm (VSP) is the major complication associated with aneurysmal SAH that results in delayed ischemic deficits in up to $25 \%$ of all cases. Although it is associated with hypercholesterolemia, chronic hypertension and atherosclerosis, there is lower incidence of VSP in older patients, probably secondary to the age-related impairment of contractility and elasticity of the muscle wall of small arteries and arterioles. However, the severity of VSP in such patients is pronounced as the margin between adequate $\mathrm{CBF}$ and the ischemic threshold may become especially narrow ${ }^{13,14,15}$.

Several limitations should be pointed out. Our report was a simplified analysis of outcome related to the age of patients and restricted to general classification according to Fisher and Hunt Hess scores and GOS. The association between age and adverse outcome is almost a constant in any disease. This is why most investigations adjust for age, but do not primarily investigate its effects. This fact may bias but not invalidate our analysis.
Then, discharge outcomes are biased because the followup times are highly variable between patients and postdischarge outcomes were not assessed. Additionally, the age of 70 years old was chosen because it is a landmark in the most important trials in literature, above what management strategies are substantially changed towards endovascular approaches.

We did not disclose important details like associated clinical morbidities, Glasgow Coma Scale, aneurysm topography, size, shape and presence of aneurysmal calcifications. We also did not discuss presence of hydrocephalus and vasospasm in our sample.

Our endovascular sample was biased, once patients submitted to endovascular treatment were already in worse clinical conditions, changing outcomes. Randomization of surgical and endovascular groups would potentially disclose different results. All those factors may surely bias our findings and interfere with inferences from the study, but not invalidate it.

Therefore, solid experimental and clinical evidence already points to similar findings and corroborate the need of evaluating aneurysmal disease in elderly with caution. A special issue that must be addressed is the increasing application of endovascular treatment in elderly, due to lower perioperative risk, similar treatment results and potential better outcomes ${ }^{1,2}$.

\section{References}

1. Connolly ES Jr, Rabinstein AA, Carhuapoma JR, American Heart Association Stroke Council, Council on Cardiovascular Radiology and Intervention, Council on Cardiovascular Nursing et al. Guidelines for the management of aneurismal subarachnoid hemorrhage: a guideline for healthcare professionals from the American Heart Association/American Stroke Association. Stroke. 2012;43(6):1711-37. http://dx.doi.org/10.1161/str.0b013e3182587839

2. International Study of Unruptured Aneurysms Investigators. Unruptured intracranial aneurysms: risk of rupture and risk of neurosurgical intervetion. N Eng J Med. 1998;339(24):1725-33. http://dx.doi.org/10.1056/NEJM199812103392401

3. Wiebers DO, International Study of Unruptured Intracranial Aneurysms Investigators. Unruptured intracranial aneurysms: natural history, clinical outcome, and risks of surgical and endovascular treatment. Lancet. 2003;362(9378):103-10. http://dx.doi.org/10.1016/ S0140-6736(03)13860-3

4. Collice M, D’Aliberti G, Arena O, Fontana RA, Bizzozero L, Solaini C et al. Multidisciplinary (surgical and endovascular) approach to intracranial aneurysms. J Neurosurg Sci. 1998;42(1 Suppl 1):S131-40.

5. Rooij NK, Linn FH, Plas JA, Algra A, Rinkel GJ. Incidence of subarachnoid haemorrhage: a systematic review with emphasis on region, age, gender and time trends. J Neurol Neurosurg Psychiatr. 2007;78912):1365-72. http://dx.doi.org/10.1136/jnnp.2007.117655

6. Proust F, Ge'rardin E, Derrey S, Lesvèque S, Ramos S, Langlois 0 et al. Interdisciplinary treatment of ruptured cerebral aneurysms in elderly patients. J Neurosurg 2010;112(6):1200-7. http://dx.doi.org/10.3171/ 2009.10.JNS08754

7. Karamanakos PN, Koivisto T, Vanninen R, Khallaf M, Ronkainen A, Parviainen I et al. The impact of endovascular management on the outcome of aneurysmal subarachnoid hemorrhage in the elderly in Eastern Finland. Acta Neurochir (Wien). 2010;152(9):1493-1502. http://dx.doi.org/10.1007/s00701-010-0714-6

8. Cai Y, Spelle L, Wang H, Piotin M, Mounayer C, Vanzin JR et al. Endovascular treatment of intracranial aneurysms in the elderly: singlecenter experience in 63 consecutive patients. Neurosurgery. 2005;57(6):1096-102. http://dx.doi.org/10.1227/01.neu.0000185583. 25420.df

9. Nieuwkamp DJ, Setz LE, Algra A, Linn FH, Rooij NK, Rinkel GJ. Changes in case fatality of aneurysmal subarachnoid haemorrhage over time, according to age, sex, and region: a meta-analysis. Lancet Neurol. 2009;897):635-42. http://dx.doi.org/10.1016/S1474-4422(09) 70126-7

10. Lanzino G, Kassell NF, Germanson TP, Kongable GL, Truskowski LL, Torner JC et al. Age and outcome after aneurysmal subarachnoid hemorrhage: why do older patients fare worse? J Neurosurg. 1996;85(3):410-8. http://dx.doi.org/10.3171/jns.1996.85.3.0410

11. Molyneux AJ, Kerr RS, Yu L-M, Clarke M, Sneade M, Yarnold JA et al. International Subarachnoid Aneurysm Trial (ISAT) of neurosurgical clipping versus endovascular coiling in 2143 patients with ruptured intracranial aneurysms: a randomised comparison of effects on survival, dependency, seizures, rebleeding, subgroups, and aneurysm occlusion. Lancet. 2005;366(9488):809-17. http://dx.doi.org/10.1016/ s0140-6736(05)67214-5

12. Bakker NA, Metzemaekers JD, Groen RJ, Mooij JJ, Van Dijk JM. International subarachnoid aneurysm trial 2009: endovascular coiling of ruptured intracranial aneurysms has no significant advantage over neurosurgical clipping. Neurosurgery 2010;66(5):961-2. http://dx.doi.org/10.1227/01.NEU.0000368152.67151.73 
13. Ryttlefors M, Enblad P, Ronne-Engström E, Persson L, llodigwe D, Macdonald RL. Patient age and vasospasm after subarachnoid hemorrhage. Neurosurgery. 2010;67(4):911-7. http://dx.doi.org/ 10.1227/neu.0b013e3181ed11ab

14. Macdonald RL, Higashida RT, Keller E, Mayer SA, Molyneux A, Raabe A et al. Randomised trial of clazosentan, an endothelin receptor antagonist, in patients with aneurysmal subarachnoid hemorrhage undergoing surgical clipping (CONSCIOUS-2). Acta Neurochir. 2013;115(Suppl):S27-31. http://dx.doi.org/10.1007/978-37091-1192-5_7

15. Torbey MT, Hauser T-K, Bhardwaj A, Williams MA, Ulatowski JA, Mirski MA et al. Effect of age on cerebral blood flow velocity and incidence of vasospasm after aneurysmal subarachnoid hemorrhage. Stroke. 2001;32(9):2005-211. http://dx.doi.org/10.1161/hs0901.094622 